\title{
Rates of Cesarean section in Al-Imamein Al-Kadhimein Medical City
}

\author{
Qabas K. Mahdi $M B C h B, D G O, C A B O G$ \\ Dept. of Obstetrics \& Gynecology, Al-Imamein Al-Kadhimein Medical City, Baghdad, Iraq
}

\begin{abstract}
Background Caesarean section rates have been increasing dramatically in the past years in Al-Imamein AlKadhimein Medical City.

Objective To determine the rate of caesarean section and to analyze the indications, so as to introduce measures to control the caesarean section rate.

Methods This retrospective study was conducted in Obstetrics and Gynecology Department at Al-Imamein AlKadhimein Medical City from $1^{\text {st }}$ Jan 2012 to $30^{\text {th }}$ Apr 2013. In this study, clinical records of all the patients who underwent caesarean section were analyzed. All cases who were underwent caesarean section whatever indication and regardless the type of caesarean section (elective, urgent, scheduled, emergent) were included in this study. Clinically diagnosed cases of ruptured uterus proved on laparotomy were excluded. Data was analyzed on SPSS version 17, Microsoft excels 2010 and frequency as well as percentages were calculated.

Results There were 10,354 deliveries during the study period (16 months) and 5897 of these were caesarean section. The rate of caesarean section was $56.95 \%$. Scheduled caesarean section was $49.31 \%$, elective caesarean section $43.89 \%$, urgent caesarean section $4.32 \%$ and emergency caesarean section $2.48 \%$.

Conclusions Caesarean section rate was high (56.95\%) in Al-Imamain AlKadhimein Medical City, the majority of patients who underwent caesarean section were scheduled and elective caesarean section. The commonest indication was repeat caesarean section.
\end{abstract}

Key words Cesarean section, Indications, Frequency

List of abbreviation: $\mathrm{CS}=$ Caesarean section, $\mathrm{RCU}=$ Respiratory care unit, $\mathrm{CEFM}=$ Continuous electronic fetal monitoring, $\mathrm{VBAC}=$ vaginal birth after a previous CS

\section{Introduction}

$\mathrm{F}$ I or most of the $20^{\text {th }}$ century, caesarians were a rarely used procedure; done only in truly life-threatening situations after all other options had been exhausted. The risks from the operation were so significant that doctors were very reluctant to use it without true need. As technology improved and caesarians became safer, doctors started doing more and more of them ${ }^{(1)}$.
Caesarean section (CS) is a relatively common procedure in modern obstetric practice; some of the obstetricians consider it to be quite simple, efficient, safe and psychologically welltolerated procedure and far superior to secondary interventions such as vacuum delivery or forceps delivery ${ }^{(2)}$.

However, CS rates vary worldwide, ranging from approximately $10 \%$ in Sweden to about $80 \%$ in private-sector hospitals in Brazil ${ }^{(3)}$.

High rates are reported from regional, tertiary public and private hospitals. These high rates are probably due to large proportions of highrisk patients attending tertiary and regional 
public hospitals and financial benefits in private sectors.

The CS epidemic is a reason for immediate concern and deserves serious international attention. The procedure is not benign and needs to be performed only when circumstances distinctly require it ${ }^{(4)}$.

\section{Is CS safe as we think?}

The possibility that indiscriminate use of CS can have a negative impact on maternal and neonatal health has been raised ${ }^{(5)}$. Even though caesareans are associated with higher rates of complications than vaginal births, they are becomingly increasingly common. Problems range from infections, including the more serious antibiotic-resistant ones, to severe bleeding, prematurity, respiratory problems for the baby, and more complications with subsequent pregnancies. There is even a small but measurably higher risk of death for the mother ${ }^{(6)}$.

A fourfold increase in maternal mortality rate associated with CS was observed even after controlling for medical and obstetric complications, maternal age, and preterm delivery ${ }^{(7)}$. Even elective CS had a 2.84 fold greater chance of maternal death as compared to vaginal birth. In UK, a twofold increase in mortality with CS was detected ${ }^{(8)}$.

Recurrent CS, scar rupture and hysterectomy are some of the future important risks. Previous CS increases the risk of multiple placental abnormalities like placental abruption, placenta previa, and adherent placentation in subsequent pregnancies ${ }^{(9)}$. The leading indication for cesarean hysterectomy in USA is placenta accrete, increta or percreta ${ }^{(10)}$. As the incidence of CS continues to rise worldwide, the problem of placenta previa and placenta accreta is likely to become more common. Obstetricians should be ready to face these future consequences of today's decision of performing $\mathrm{CS}^{(11)}$.

\section{Incidence}

The consensus recommendation for optimal CS rate of $10-15 \%$ was made by world health organization (WHO) in $1985^{(12)}$. The limitation issue is being debated by professionals and women's groups in most parts of developed world based on risks and benefits ${ }^{(13)}$.

Efforts to bring down the rate have failed and it is on a steady rise. Caesarean section rates are high and continue to rise in developed countries (14). However, the impact of guidelines and recommendations in curbing their growth has been limited: in 1985, representatives of a study group convened by the World Health Organization wrote, "there is no justification for any region to have caesarean section rates higher than $10-15 \%{ }^{(12)}$. Although, levels of $10-15 \%$ were considered high but acceptable at the time, average caesarean rates in most developed regions (with the exception of Eastern Europe) now exceed 20\%; the recommendation thus appears to have been largely overtaken by events ${ }^{(15)}$.

In Sweden, Denmark and Netherlands, the CS rate is still close to $10 \%$ with some of the world's lowest maternal and perinatal mortality rates ${ }^{(5)}$. In 2001, an estimated $21.4 \%$ of all deliveries in England and Wales were by CS, a fivefold increase since $1971^{(16)}$. In 2007, nearly one-third (32\%) of all births were cesarean deliveries in USA ${ }^{(17)}$.

Since 1996, CS deliveries have increased by more than $40 \%{ }^{(18)}$. This may be due to more conservative clinical practice and legal pressures ${ }^{(19)}$.

The rising trend in CS is definitely not limited to USA and UK. In Ireland, the CS rate now exceeds $26 \%{ }^{(20)}$.

In Saudi Arabia the overall CS rate significantly increased by $80.2 \%$, from $10.6 \%$ in 1997 to $19.1 \%$ in $2006^{(21)}$.

Regarding our country, almost $26 \%$ of Iraqi women giving birth at public hospitals do so via CS according to the 2010 health report for the Iraqi Health Ministry ${ }^{(22)}$; and in 2012, the rate was further increased to $29.25 \%{ }^{(23)}$. 
WHO has since finessed its position on CS rates by stating that the most important issue is that every woman who needs a CS should have one. It acknowledges that there is little scientific evidence to support a $15 \%$ CS rate ${ }^{(24)}$.

Against this background, this study was done to assess the indications of CS \& caesarean delivery rates in Al-Imamein AL-Kadhimein Medical City in order to identify patient groups with an increasing risk for CS.

\section{Methods}

A retrospective analysis of 10,354 deliveries was carried out at Al-Imamein Al-Kadhimein Medical City, (which is a tertiary teaching center with a respiratory care unit (RCU) unit contain $24 \mathrm{RCU}$ beds and maternity unit consist of maternity and gynecology ward with 124 beds), to examine the factors responsible for the high CS rates during the period from $1^{\text {st }}$ Jan. 2012 to $30^{\text {th }}$ Apr. 2013.

It included all the pregnant ladies (booked, non-booked) who were admitted through emergency or outpatient department. According to urgency of CS they were grouped into four categories: urgent, emergency, scheduled and elective CS ${ }^{(25)}$. Distribution of patients who had $1^{\text {st }}$ CS according to parity (primigravida or multigravida) and percentage of recurrence of CS, assessment of patients who achieved vaginal delivery according to their parity and history of previous one CS then the major and miscellaneous indications of CS were categorized. The patients with clinical diagnosis of ruptured uterus, which later proved on laparotomy, were excluded from the study). The data was analyzed on SPSS version 17 and microsoft excel 2010 and frequency and percentages were calculated.

\section{Results}

The caesarean section rate (CSR), in general, was $56.95 \%$ births. (Fig. 1), and $48.8 \%$ of the caesareans were scheduled procedures, 43.26\% elective, $4.95 \%$ urgent and $2.98 \%$ emergency (Fig. 2).

The caesarean section rate was high among primigravida (53.08\%) versus $46.92 \%$ vaginal delivery (Fig. 3), and the rate of $1^{\text {st }}$ CS in primigravida was $48.69 \%$ and $51.31 \%$ in multigravida (Fig. 4).

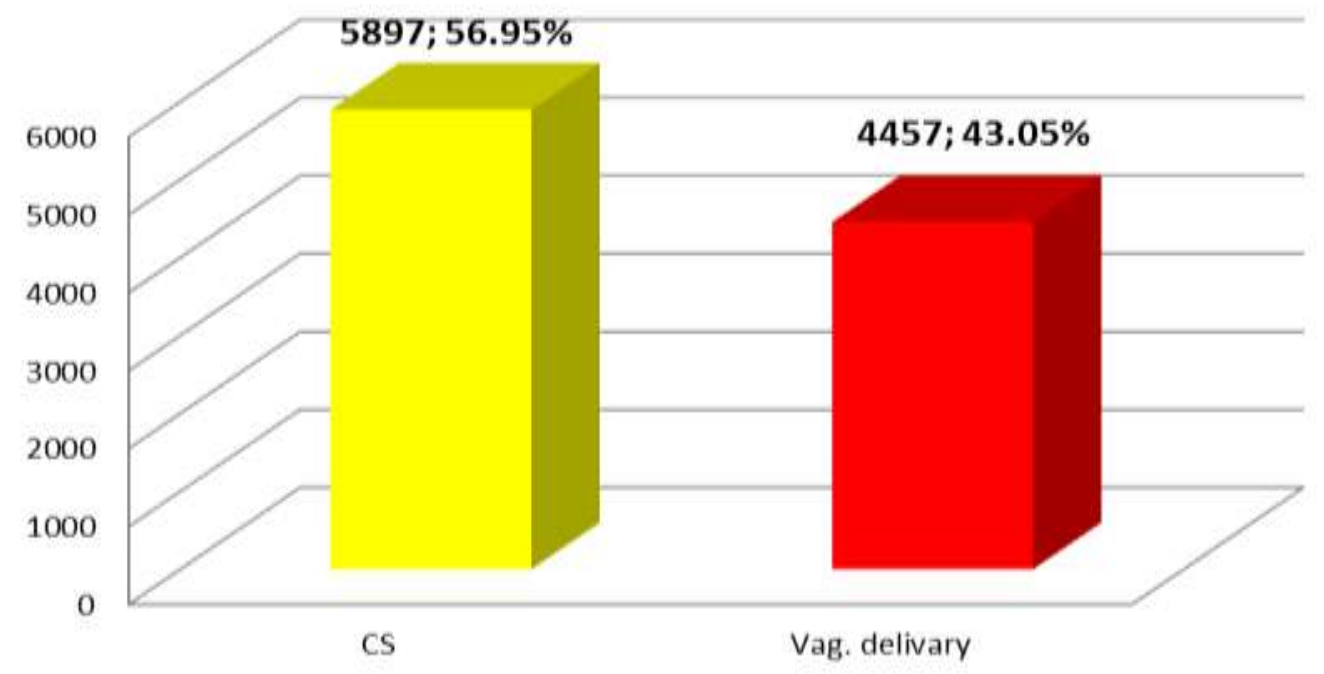

Fig. 1. Rate of CS and vaginal delivery 


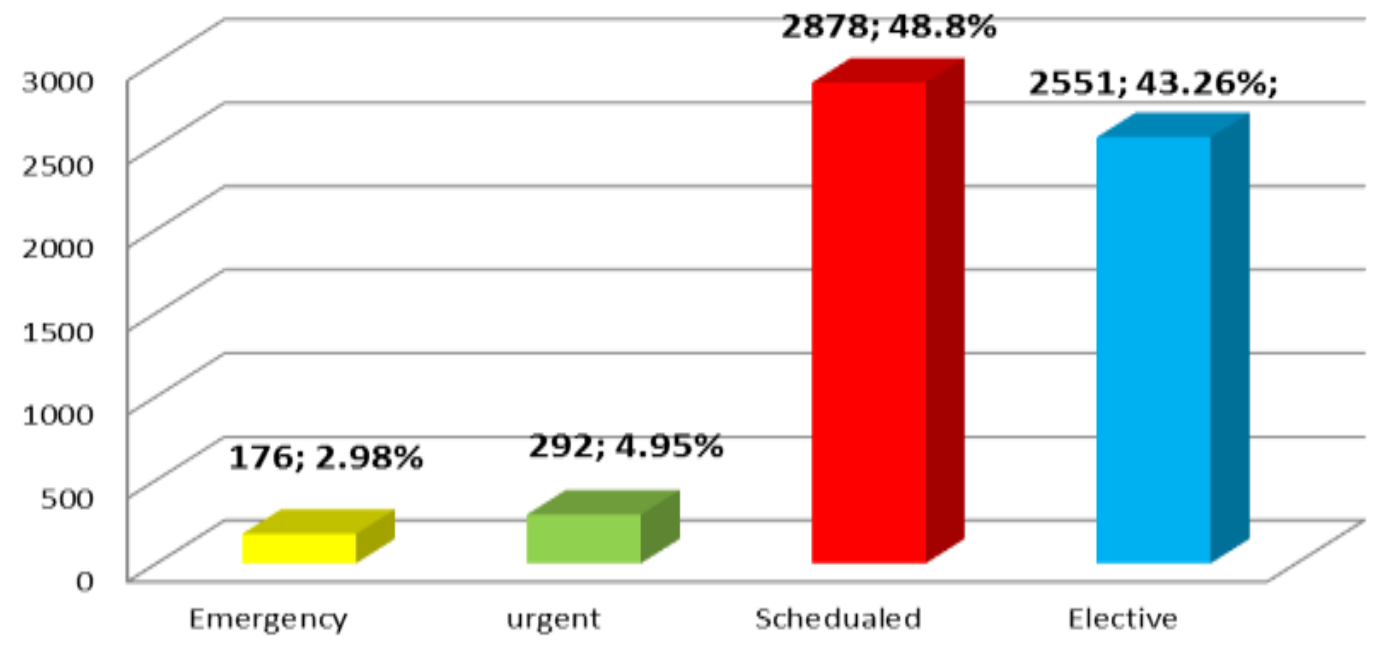

Fig. 2. Distribution of CS according to type

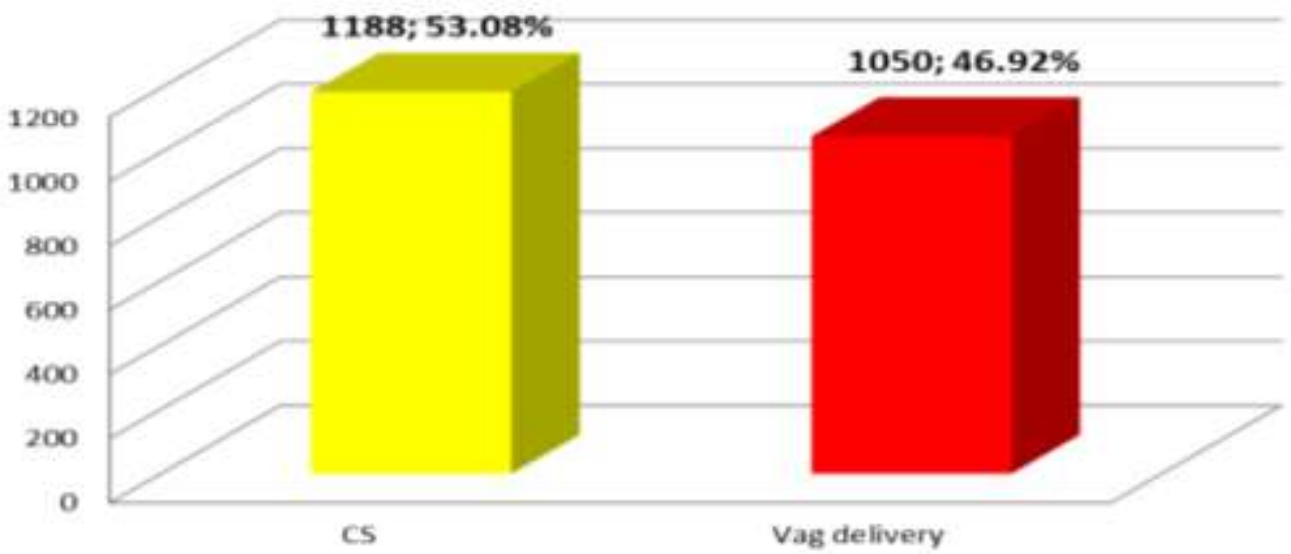

Fig. 3. Types of delivery for primigravida women included in the study

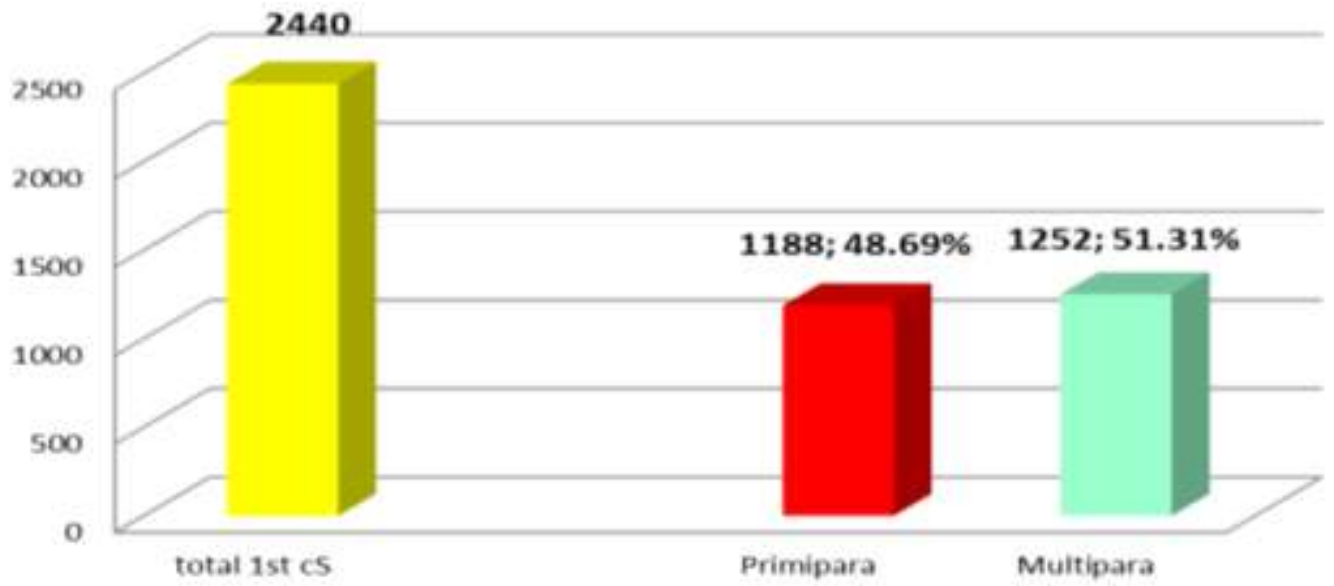

Fig. 4. Distribution according to types of CS\& parity 
The first CS rate was $41.38 \%$, second CS rate was $28.69 \%$ and more than 2 CS rate was $29.93 \%$ (Fig. 5), While VBAC (vaginal birth after CS) was low, the rate was $4.6 \%$ and percentage of primipgravida among women who were delivered vaginally were $23.56 \%$. (Fig. 6).

The four leading indications were recurrent section (29.93\%), labor dystocia (11.04\%), hypertensive disorders (8.29\%) and fetal distress (8.29\%) (Fig. 7), while $20.56 \%$ patients had miscellaneous indications for CS (Fig. 8). The most common indications were prelabor rupture of membranes (PROM) (3.91\%), intrauterine growth retardation (IUGR) and scanty liquor (3.73\%), infertility (3.49\%), medical disorders (3.01\%) and bad obstetrical history $\mathrm{BOH}$ (3.35\%).

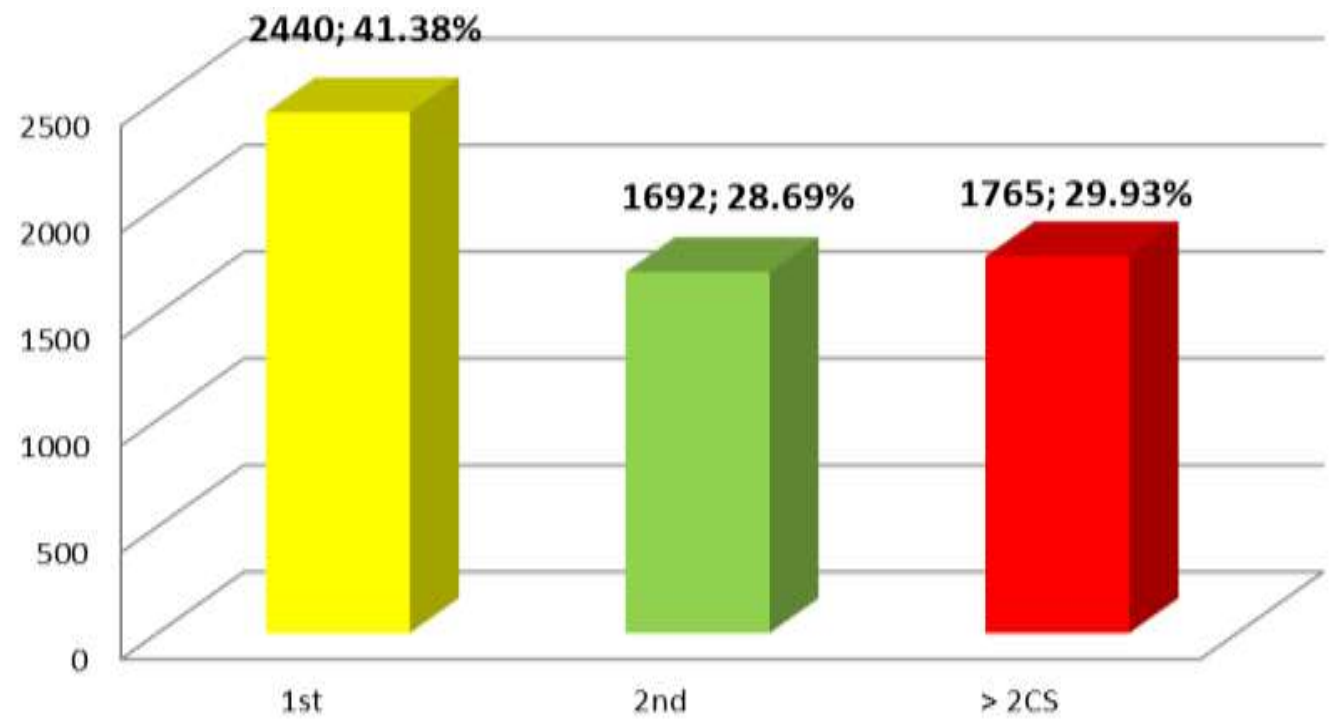

Fig. 5. Number and percentage of recurrence of CS

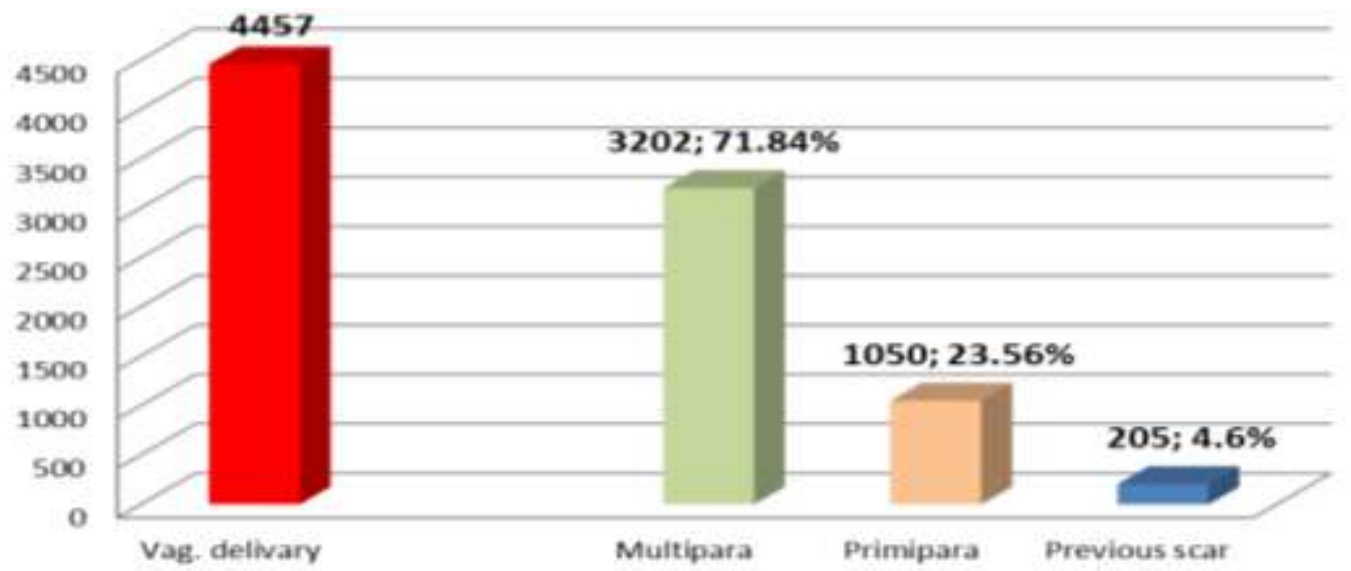

Fig. 6. Distribution of patient who achieved vaginal delivery according to their parity and history of previous one CS 


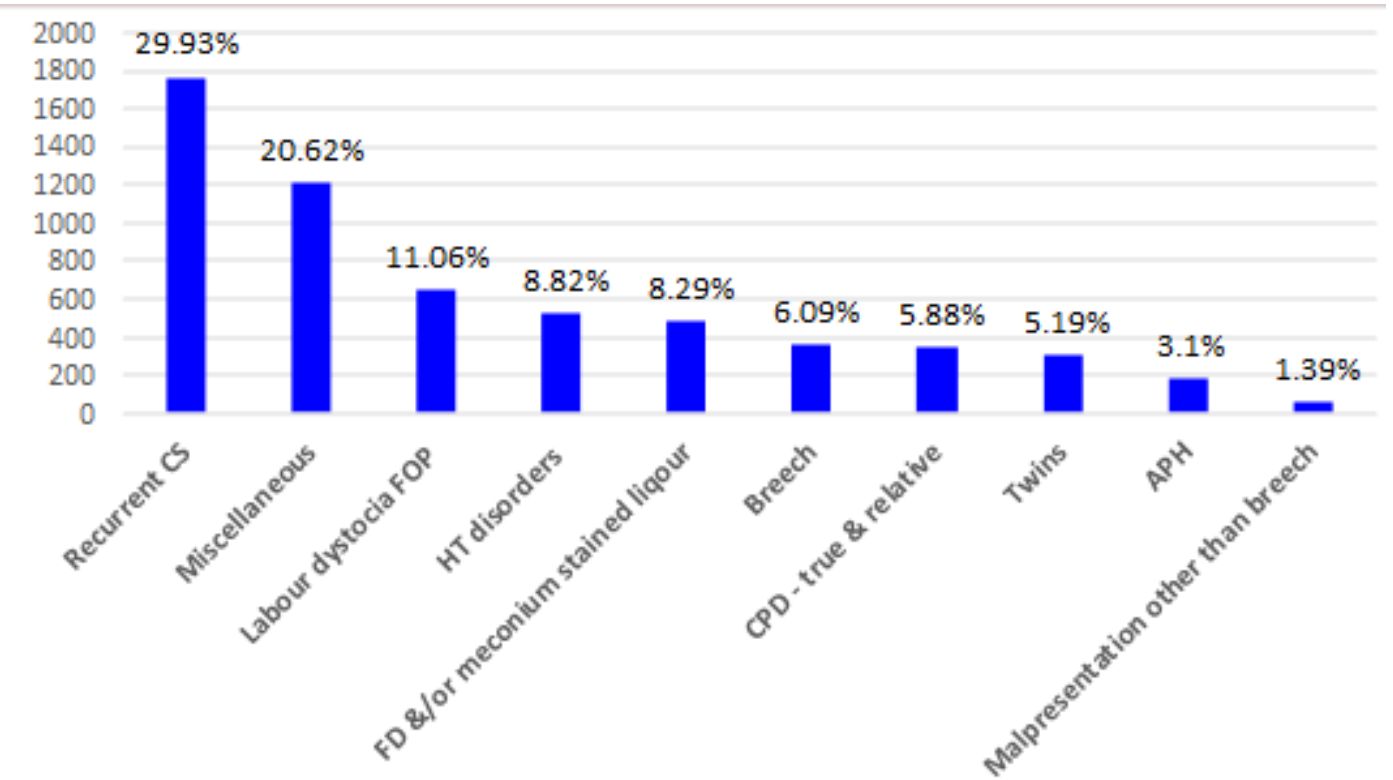

Fig. 7. Major indications for CS. FOP: failure of progress, HT: hypertension, FD: fetal distress, CPD: cephalopelvic disproportion, APH: antepartum hemorrhage

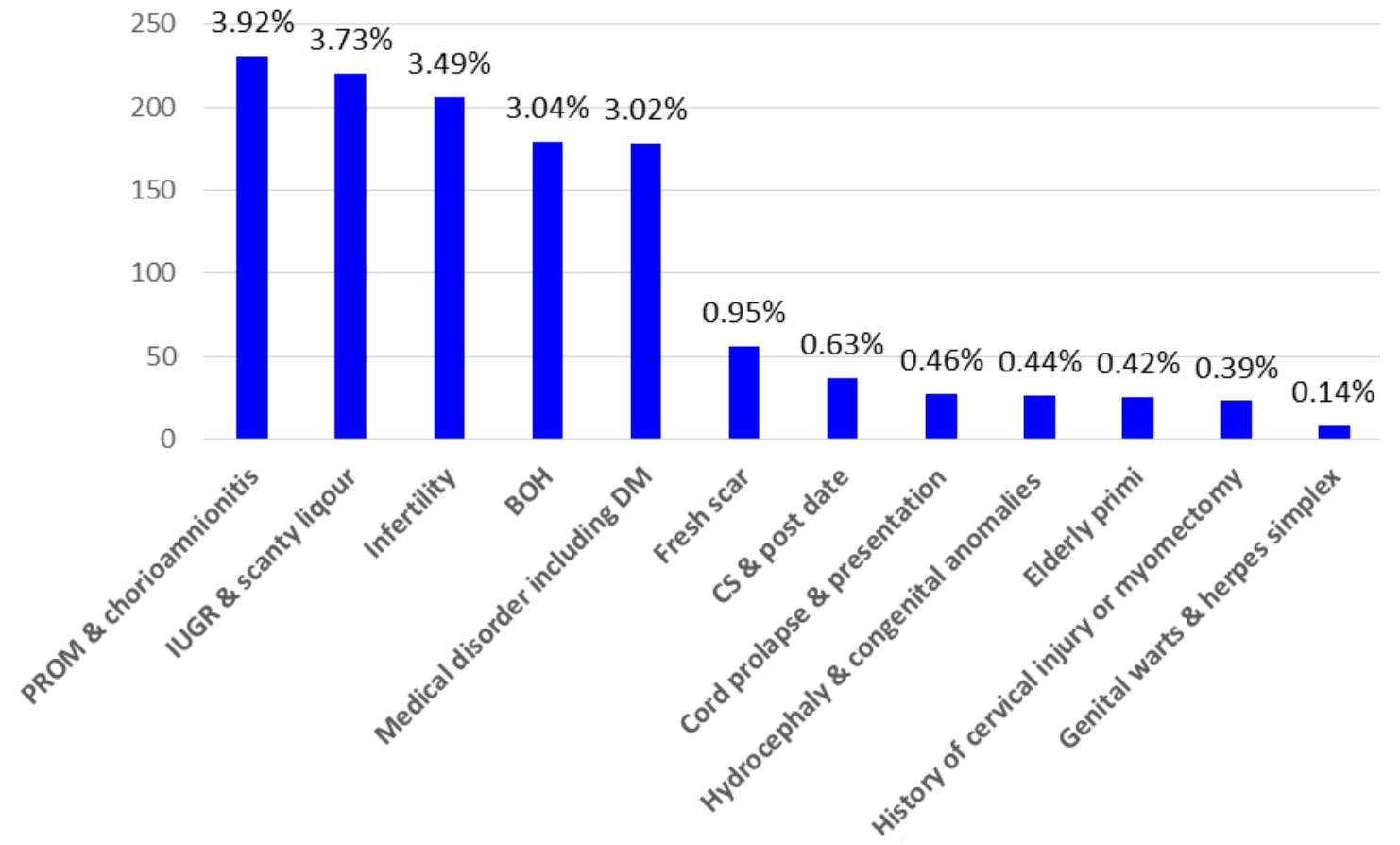

Fig. 8. Miscellaneous indication for CS. PROM: prelabor rupture of membranes, IUGR: intrauterine growth restriction, $\mathrm{BOH}$ : bad obstetrical history

\section{Discussion}

Almost half of all deliveries performed from the first of Jan. 2012 to the $30^{\text {th }}$ of Apr. 2013 in the Al-Imamein Al-Kadhimein Medical City were by CS. It is important to emphasize that these findings are not meant to be generalized to the city or country.

The rate expected to be high as it is a tertiary referral center and it served high-risk, referred patients in addition to low risk group, but usually 
those with low-risk are delivered at maternity hospitals or at home by traditional birth attendants.

In comparing studies and statistics, the rates also high, it was $64.7 \%$ in Isra university Hospital Hyderabad ${ }^{(2)}, 33.7 \%$ in a tertiary referral center in Eastern Nepal in $2007^{(26)}, 34.5 \%$ in a tertiary hospital in the Niger Delta, Nigeria ${ }^{(27)}$, and in USA, Arkansas State hospitals in 2012, the rate was ranging between $40.4-50.9 \%{ }^{(28)}$.

Specific child bearing patterns of our women, large families, flaws in antenatal surveillance, absence of a referral system and departmental polices regarding management of cases with labor dystocia, previous CS and fetal distress seem to be the major underlying causes of the high CS rate causing a marked spike in the number of scheduled CS performed in our unit. The reasons for the dramatic increase in CS rates though not obvious are somewhat complex. The indications for performing CS have changed a lot in recent years and keep on changing for varied circumstances. Most CS are currently performed to benefit the fetus, not the mother.

It is sad that CS are frequently and arbitrarily performed for fetal distress and prolonged labor without due respect to correct diagnosis and unbiased decision ${ }^{(29)}$.

In this study fetal distress was based on pathological and non-assuring cardiotocography, which based on continuous electronic fetal monitoring (CEFM) although this not reduce the overall perinatal mortality and the incidence of cerebral palsy ${ }^{(30)}$.

Many options have been tried to replace CEFM or to improve its predictability for fetal distress, such as fetal blood sampling, fetal pulse oximetry and analysis of fetal electrocardiogram. However, all are still being used in clinical trials and further studies are needed ${ }^{(31)}$.

Recurrent sections are now frequently performed for various reasons. A trial for vaginal birth after a previous CS (VBAC) is considered safer than a routine repeat CS. But, it is unfortunate that there is currently less enthusiasm for VBAC by trial of scar or of labor.
It is evident that whereas CS is doctor friendly, VBAC is not.

It was notices that VBAC was low (4.6\%) but all over the world the rate decline and keep on declining; the rate of VBAC in USA is down from $17 \%$ in 1996 to $11 \%$ in $1999^{(32)}$ and furthermore decrease to $10.2 \%$ in $2012^{(33)}$.

The term fresh scar (related to pregnancy happened within 6 months following CS is over used with no scientific bases. (0.95\% of cases); Royal College of Obstetrics and Gynecology (RCOG) recommended that all women previously delivered by one lower segment CS should be offered an opportunity to labor during their next pregnancy by promoting a trial of scar or of labor (29). In addition, cases of previous one CS and postdate $(0.63 \%$ of cases), no induction of labor was done due to fear of uterine rupture although augmentation is not contraindicated it should only be preceded by careful obstetric assessment, maternal counselling and by a consultant-led decision ${ }^{(34)}$. Induction of labor and failed induction contribute to increase CS rates also. Other reasons included; lack of adherence to standard guidelines and protocols for managing labor and non-availability of system of audit for CS rates.

Other indications such as precious pregnancy, poor Bishop Scores in postterm pregnancies and CS decision in primigravida and previous scar not always made by senior obstetrician, were also contributed causes for increase CS rate.

Defensive obstetrics is another common reason for high rates of CS, as it has been observed that $82 \%$ of physicians performed CS to avoid negligence claims ${ }^{(16)}$. Defensive obstetrics violates the fundamental principle of medical practice. In any case it does not work. During the years that defensive obstetrics has grown in numbers, there has been no slowdown in litigation ${ }^{(35)}$.

This is closely related to daylight obstetrics for the obstetrician's convenience. Elective and scheduled CS are set in favor of weekdays and daylight. It takes usually 30-45 minutes to perform a CS while conducting a vaginal birth 
may need 12 hours or more heavily taxing on the obstetrician's time and patience.

It was concluded from this study, CS rate was high (56.95\%) in Al-Imamein Al-Kadhimein Medical City; the majority of patients who underwent CS were scheduled and elective CS. The commonest indication was repeat CS.

Thefollowing are recommendations from this study:

1. In order to turn back the current CS trend, our main target need to be the low-risk primipgravida and previous one CS, in order to avoid unnecessary CS in these groups and to reduce the number of repeat $C S$ in the future.

2. To successfully increase access to VBAC: Iraqi National Guideline and protocol for VBAC should be introduced and applied in all ministry hospitals.

3. Accurate registration of the main indication for CS, a clear and strict CS audit tool should be applied in the maternity unit.

4. Efforts to keep CS rate around certain level is needed, a nation-wide committee that involves policy makers, social leaders and obstetricians is required.

\section{Acknowledgment}

I would like to express my gratitude and appreciation for Dr. Majid H. Ahmed who helped me in completing the statistical analysis of this study.

\section{Conflict of Interest}

The author have no conflicts of interest.

\section{Funding}

None.

\section{References}

1. A History of VBACs and Cesareans in the USA, 2009. blogger.com

(http://wellroundedmama.blogspot.com/2009/03/hist ory-of-vbacs-and-cesareans-in-usa.html). Accessed at $10 \backslash 3 \backslash 2014$.

2. Haider $G$, Zehra N, Munir AA, et al. Frequency and indications of cesarean section in a tertiary care hospital. Pak J Med Sci October. 2009; 25(5): 791-6.
3. Naidoo N, Moodley J. Rising rates of Caesarean sections: an audit of Caesarean sections in a specialist private practice. SA Fam Pract. 2009; 51(3): 254-2.

4. Mukherjee SN. Rising cesarean section rate. J Obstet Gynecol India. 2006; 56(4): 298-300.

5. Wagner M. Choosing caesarean section. Lancet 2000; 356: $1677-80$

6. Cupaiuolo $C$. The Rising rate of C-Sections exemplifies what's wrong with U.S. healthcare. June 28, 2010. http://www.ourbodiesourblog.org/blog/2010/06/therising-rate-of-c-sections-exemplifies-whats-wrongwith-u-s-healthcare

7. Harper MA, Byington RP, Espeland MA, et al. Pregnancy related death and health care services. Am J Obstet Gynecol 2003; 102: 273-8.

8. Confidential enquiries into maternal deaths in UK. London. RCOG Press. 2001.

9. Zelop C, Heffner LJ. The downside of cesarean delivery: short and long-term complications. Clin Obstet Gynecol. 2004; 47: 386-93.

10. Catanzarite VA, Lorrain MS, Schrimmer DR, et al. Managing placenta previa accreta. Contemp Obstet Gynecol. 1996; 41: 66-95.

11. Chung $\mathrm{CL}$, Cheng $\mathrm{PJ}$, Liang $\mathrm{CC}$, et al. Obstetrical hysterectomy and placenta previa / accreta. Three bladder injury case reports. Change Gung Med J. 1997; 20: 44-51.

12. World Health Organization, Human Reproduction Programme. WHO statement on caesarean section rates. WHO/RHR/15.02. 2015.

(http://www.who.int/reproductivehealth/publications/ maternal_perinatal_health/cs-statement/en/)

13. Anderson GM. Making sense of rising cesarean section rates - Timeto change our goals. BMJ. 2004; 329: 6967.

14. Lauer JA, Betrán AP, Merialdi $M$ and Wojdyla D. Determinants of caesarean section rates in developed countries: supply, demand and opportunities for control. World Health Report, 2010 Background Paper, No 29.

15. Lauer JA, Betrán AP. Decision aids for women with a previous caesarean section: focusing on women's preferences improves decision-making. BMJ. 2007; 334: 1281-2.

16. Sur S, Mackenzie IZ. Does discussion of possible scar influence preferred mode of delivery after cesarean section? J Obstet Gynecol. 2005; 25: 338-41.

17. Menacker F, Hamilton BE. Recent trends in cesarean delivery in the United States. NCHS Data Brief. 2010; 35: 1-8.

18. Center for Disease Control and Prevention. C-sections rise, so do premature births. Hindustan Times. New Delhi. 2005; 23 Nov.

19. MacDorman MF, Menacker F, Declercq E. Cesarean birth in the United States: epidemiology, trends, and outcomes. Clin Perinatol. 2008; 35(2): 293-307.

20. O'Dwyer V, Turner MJ. Is the caesarean section rate in Ireland too high? Ir Med J. 2011 May; 104(5): 133-4. 
21. Ba'aqeel HS. Cesarean delivery rates in Saudi Arabia: $A$ ten-year review Ann Saudi Med. 2009 May-Jun; 29(3): 179-83.

22. Ministry of Health, Republic of Iraq, Annual report, 2010.

23. Ministry of Health, Republic of Iraq, Annual report, 2012.

24. Chaillet N, Dumont A. Evidence-based strategies for reducing cesarean section rates: a meta-analysis. Birth. 2007; 34(1): 53-64. Review.

25. Royal College of Obstetricians and Gynaecologists Clinical Effectiveness Support Unit. The National Sentinel Caesarean Section Audit Report. London: RCOG Press; 2001: 49-53.

26. Chhetri S, Singh U. Caesarean section: its rates and indications at a tertiary referral center in Eastern Nepal. HR 2011; 9(3): 179-183. DOI: http://dx.doi.org/10.3126/hren.v9i3.5587.

27. Igberase GO, Ebeigbe PN, Andrew BO. High caesarean section rate: a ten year experience in $A$ tertiary hospital in the Niger Delta, Nigeria. Niger J Clin Pract. 2009 Sep; 12(3):294-7.

28. http://www.cesareanrates.com/blog/2013/7/16/topten-highest-arkansas-cesarean-rates2012.html\#sthash.tUVncWmB.dpuf accessed at8/3/2014.

29. Thomas J, Parenajothy S. Royal College of Obstetricians and Gynecologists clinical effectiveness support unit.
The national sentinel caesarean section audit report. London. Royal College of Obstetricians and Gynecologists Press. 2001.

30. American congress of obstetrician and gynaecologist (RCOG). The National Sentinal cesarean section audit report, RCOG clinical effectiveness support unit, London (UK): RCOG; 2001. p.1

31. Bondok WM, El-shehry SH, Samira M. Fadellallah SM. Trends in cesarean section rates. Saudi Med J. 2011; 32(1). 41-5.

32. Editorial. Cesarean section on the rise. Lancet 2000; 356; 1697.

33. CDC/National Center for Health Statistics. 2003 Revisions of the U.S. Standard Certificates of Live Birth and Death and the Fetal Death Report. (http://www.cdc.gov/nchs/nvss/vital_certificate_revisi ons.htm.) Page last updated: July 17, 2012.

34. Royal College for Obstetrician and Gynecologists. Birth after previous caesarean birth. Green-top Guideline No. 45, February 2007.

35. Mackenzie IZ, Cooke I, Annan B. Indications for cesarean section in a consultant unit over three decades. J Obstet Gynecol. 2003; 23(3): 233-8.

E-mail: almarsumiqabas@yahoo.com Received 24 ${ }^{\text {th }}$ Jan.2016: Accepted $9^{\text {th }}$ Jun. 2016 